\title{
How to Motivate Engineering and Technical Personnel to Innovate? The Impact of Human Resource Management Strength on Employee Innovation Behavior
}

\author{
Yang Ruijuan $^{1 \mathrm{st}, 1}$, Song Jiale*2nd,2, Shi Chengli ${ }^{3 \mathrm{rd}, 3}$ \\ ${ }^{1}$ Economics and Management school Xi'an Shiyou University Xi'an, China \\ ${ }^{2}$ Economics and Management school Xi' an Shiyou University Xi'an, China \\ ${ }^{3}$ Taizhou Jing Yang Industrial Co., Ltd. Taizhou, China
}

\begin{abstract}
Based on a survey of 611 engineering and technical personnel in Chinese manufacturing enterprises, this paper uses hierarchical regression analysis and structural equation model to examine the influence path of human resources management strength on employee innovation behavior. Further, the Bootstrap method was used to test the mediating effect. The results show that human resource management strength has a significant positive impact on employee innovation behavior and its two dimensions. Organizational atmosphere and employee psychological conditions play multiple mediating roles between human resource management strength and employee innovation behavior. Compared with employees' psychological conditions, organizational atmosphere has a more significant mediating effect on innovation ideas generate. There is no significant difference between the mediating effect of organizational climate and employee psychological conditions on the implementation of innovation ideas generate.
\end{abstract}

\section{INTRODUCTION}

Innovation is the most important quality of business operation. China's development is still in a period of strategic opportunities. The economic structure has been continuously improved and upgraded, and the driving force of development is gradually shifting to innovation. To play the main role of innovation, enterprises need good innovation ability, and stimulating employee innovation behavior (EIB) is the key to improving enterprise innovation ability ${ }^{[1]}$. However, most employees in enterprises just follow the rules to complete their work and seldom take the initiative to innovate. As the main undertaker of enterprise innovation, engineering and technical personnel seldom take the initiative to innovate. Why do so few employees take initiative to innovate? What factors affect EIB?

A large number of studies have proved from a macro perspective that human resource management (HRM) measures can promote the improvement of enterprise performance ${ }^{[2]}$, but few studies have focused on the key role of employees in the chain of "human resource management-enterprise performance" from a micro perspective ${ }^{[3]}$. In enterprise management activities, due to the interference of individual differences, external environment and other factors, it is inevitable that information omission and distortion will occur in the process of conveying HRM measures, which will lead to employees' behaviors that deviate from the work requirements. Once such behavior occurs, HRM measures will hinder the development of the enterprise. Therefore, it is impossible for an enterprise to improve its performance only by imitating and copying a set of scientific and reasonable HRM measures. It is only by focusing on the implementation effect of HRM measures that the enterprise can improve its performance. Employee only clear and correct perception of HRM measures, to be able to do the work better for the enterprise. Bowen and Ostroff ${ }^{[4]}$ proposed the human resource management strength (HRMS) used to describe the employee perception of enterprise HRM practice. A high level of HRMS will create a strong situation to promote employees' effective cognition of HRM measures, which is conducive to promoting EIB.

The strong context created by the intensity of HRM can convey the innovative behaviors desired by the company to employees, affect their cognition, and promote their active innovation. That is to say, the cognitive ability of employees (OA and EPC) is HRMS on the intermediary variables in the process of EIB. On the other hand, EIB includes two stages of innovation ideas generate(IIG) and innovation ideas execution(IIE), which is a complex multistage continuous process, but more studies only regards EIB as a kind of behavior, there is a lack of specific research on the different stages of EIB.

To sum up, HRMS is the independent variable, EIB is the dependent variable, OA and EPC are the mediating variables. The research model is shown in Figure 1. 


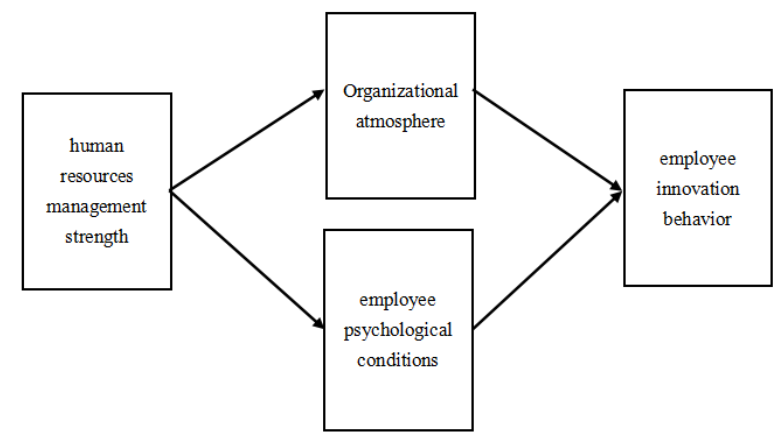

Figure 1 Theoretical model

\section{THEORETICAL ANALYSIS AND HYPOTHESIS DEDUCTION}

\subsection{HRMS and EIB}

Existing studies have focused on content orientation, focusing on the impact of HRM measures on EIB. But whether these measures can be effective depends more on whether employees can correctly recognize and accept these measures. Therefore, if an enterprise wants employees to take the initiative to innovate, they should pay more attention to the implementation effects of specific measures to ensure that employees can agree with the company's HRM information. Bowen divided the HRMS into three dimensions: distinctiveness, consistency and consensus. Distinctiveness means that the company's HRM system can arouse the interest of employees and are motivated to work; consistency means that the "signals" released by various HRM measures are consistent and will not contradict each other, and employees obtain more information Stability, which can effectively adjust work behavior; consensus means that HRM measures can be universally recognized by managers at all levels of the enterprise and ordinary employees. As an environmental variable, HRMS can affect the active behavior of employees ${ }^{[5]}$. The higher the HRMS, the more likely it is to form a strong situation, which can help employees effectively understand HRM measures and show the innovation behaviors expected by the enterprise.

EIB includes IIG and IIE. IIG refers to the employees found that there are opportunities to improve technology, services, products, etc. in their work, thereby generating novel and effective new ideas, and conducting feasibility tests. IIE refers to that employees mobilize all resource to make innovative ideas a part of enterprise operation after IIG ${ }^{[6]}$.A high level of HRMS can effectively convey corporate goals to employees. When employees understand these goals, they will actively seek opportunities in work, generate and try out new ideas. According to the attribution theory, a high level of consistency and consensus will make employees actively attribution to "innovative behavior-work reward", so as to implement innovative ideas into innovative practices. Based on the above analysis, this study puts forward the following hypotheses:

H1: HRMS significantly positively affects EIB; H1a: HRMS significantly positively affects IIG; H1b: HRMS significantly positively affects IIE.

\subsection{Mediating Role of OA}

Duan summarized previous studies and defined OA as the individual's subjective perception of the organizational environment ${ }^{[7]}$. When the perceptions of different individuals in the organization reach agreement to some extent. It includes three dimensions: friendly relationship, innovative atmosphere and fair atmosphere. This definition emphasizes that the $\mathrm{OA}$ is the result of the interaction between the individual and the environment.

A high level of HRMS will reduce employees' perception of uncertainty and risk, so it is easier to form a stable relationship with the organization ${ }^{[8]}$.Effective organizational management can promote employees to have a clear understanding of the OA, and then show the behavior expected by the organization. The distinctiveness dimension of HRMS emphasizes that management measures can arouse employees' interest and attention, aiming at making employees actively understand the innovation activities of the organization. The consistency dimension describes the gap between the implementation result and the expected effect of management measures. The higher the intensity of consistency is, the stricter the implementation of management measures is, which is conducive to employees' perception of a fair organizational atmosphere. Consensus dimension focuses on employees' sense of identity for management measures and their perception of whether management measures are fair and just. Based on the above analysis, this study puts forward a hypothesis:

H2: HRMS significantly positively affects OA.

In the stage of IIG, employees will determine the innovation goal to be realized or the problem to be solved through the strong motivation to solve the problem or the promotion of external environment ${ }^{[9]}$. When employees are in an organization that supports innovation and is more tolerant, they feel less social pressure to come up with innovative ideas. In the stage of IIE, employees need not only to have the ability to implement innovation, but also to seek the help of other organization members. In a harmonious OA, employees are more willing to help each other, and it becomes easier to realize innovative ideas. Based on the above analysis, this study puts forward the following hypotheses:

H3: OA significantly positively affects EIB;

H3a: OA significantly positively affects IIG;

H3b: OA significantly positively affects IIE.

According to the classical psychological research paradigm of "Stimulus-Organism-Response" (S-O-R), HRMS affects employees' perception of the management environment and work atmosphere, and then they choose whether to innovate or not. Based on the theory of planned behavior, when an organization shows an atmosphere of expecting employees to innovate, this atmosphere will promote employees to come up with novel innovative ideas. When employees have a clear understanding of the causal relationship of "behavior-reward" in HRM measures and the OA is relatively harmonious, innovative ideas can be transformed into innovative behaviors. Based on the above analysis, this study puts forward the following hypotheses:

H4: OA plays a mediating role between HRMS and 
EIB; IIG;

H4a: OA plays a mediating role between HRMS and IIE.

H4b: OA plays a mediating role between HRMS and

\subsection{Mediating Role of EPC}

Employees' attitude towards work depends on their own psychological perception of the work environment. Therefore, EPC should include three dimensions: psychological meaning, psychological safety, and psychological effectiveness, reflecting the physical, psychological and emotional willingness of employees to work ${ }^{[10]}$. Guzzo believes that employees will understand the working environment through HRM information [11].

High distinctiveness will enable employees to have a clear understanding of the organization's various management systems. High consistency indicates that the organization's HRM measures are consistent, and there is no contradiction among the measures. Employees believe that they will be paid after working hard, so they take their work seriously. High consensus will make employees perceive that they have a common vision within the organization, and will not worry about expressing their true self and adversely affecting their own image and career. Based on the above analysis, this study proposes hypotheses:

H5: HRMS significantly positively affects EPC.

According to the theory of planned behavior, behavior attitude, subjective norms and perceived behavior control are the three main variables that determine behavior intentions. The dimension of psychological meaning involves employees' judgment on the value of innovative behavior, and belongs to the category of behavioral attitudes. The psychological safety dimension involves the environmental pressure that employees face when they implement innovation, and determines the extent to which employees display their true selves. It belongs to the category of subjective norms. The dimension of psychological effectiveness relates to the resource preparation of employees for innovation, which can promote or hinder EIB, which belongs to the category of perceptual behavior control. It can be seen that the psychological state of employees will directly affect the behavior intention of employees, which reflects the degree to which employees are willing to try to innovate and work hard for it.

From the two stages of EIB, when employees' work stress levels are low, their mental state is more relaxed, they can find new opportunities at work, and they are more willing to express and showcase their innovative ideas, thereby promoting the IIG ${ }^{[12]}$. Although employees have strong ideas to implement innovation, they may not adopt innovative behaviors due to lack of resource support or insecurity ${ }^{[13]}$. Psychological effectiveness describes employees' perception of the resources needed to carry out innovative work. The higher the psychological effectiveness, the more willing employees are to innovate. This shows that a high-level EPC can promote EIB. Based on the above analysis, this study proposes hypotheses:
H6: EPC significantly positively affects EIB;

H6a: EPC significantly positively affects IIG;

H6b: EPC significantly positively affects IIE.

The high-speed flow of information will make employees understand that the organization has a supportive attitude towards innovative behaviors, which can improve psychological meaning, psychological safety and psychological effectiveness, so that they can implement and implement innovative ideas without pressure. According to the "SOR" research paradigm, the strong context brought about by HRMS will enable employees to make correct causal attributions between "behavior and result" ${ }^{[14]}$, thereby stimulating EPC and willingness make innovative behaviors that the organization expects. Based on the above analysis, this study proposes hypotheses: EIB;

H7: EPC plays a mediating role between HRMS and

H7a: EPC plays a mediating role between HRMS and IIG; IIE.

H7b: EPC plays a mediating role between HRMS and

\section{MATERIALS AND METHODS}

\subsection{The Pre-investigation}

In order to ensure the scientificity and rigor of the research, a pre-investigation was carried out in a state-owned enterprise and some manufacturing enterprises in Shaanxi Province before the formal study. The employees were invited to fill in the questionnaire. 144 questionnaires were collected, of which 119 were valid, and the effective rate was $82.6 \%$.Modify some questions according to the preliminary research results.

\subsection{The Formal Investigation}

After the modification is completed, a formal survey will be conducted. Questionnaires were issued to engineering and technical personnel in manufacturing enterprises in Shaanxi Province, and 732 questionnaires were returned, of which 611 were valid questionnaires, with an effective rate of $83.5 \%$

\subsection{Variable Measurement}

All variables are scored using Likert's five-point method. "1" means "completely disagree" and "5" means "completely agree".

HRMS: The HRMS scale designed by three dimensions of distinctiveness, consistency and consensus, with a total of 31 items $^{[15]}$. The Cronbach's $\alpha$ coefficient of the scale in this study was 0.936 .

OA: The OA scale includes three dimensions: friendly relationship, innovative atmosphere and fair atmosphere, with a total of 10 items $^{[16]}$. The Cronbach's $\alpha$ coefficient of the scale in this study was 0.846 .

EPC: The EPC scale includes three dimensions: psychological meaning, psychological safety, and 
psychological effectiveness, with a total of 15 items ${ }^{[17]}$. The Cronbach's $\alpha$ coefficient of the scale in this study was 0.884 .

EIB: The EIB scale includes two dimensions: IIG and IIE, with a total of 12 items ${ }^{[6]}$. The Cronbach's $\alpha$ coefficient of the scale in this study was 0.908 .

\section{DATA ANALYSISI AND RESULTS}

\subsection{Discriminative Validity Test}

Since the questionnaires in this study are all answered by the staff, the structural validity test is firstly carried out. The results of confirmatory factor analysis are shown in Table 1. The fitting indicators of the four-factor model were: $\chi^{2}=1863.263, \mathrm{df}=1273, \chi^{2} / \mathrm{df}=1.464, \mathrm{GFI}=0.902$,
RMSEA $=0.028, \mathrm{CFI}=0.967, \mathrm{NFI}=0.904$, which proves the four variables in this study The discriminative validity was good.

Table 1 Confirmatory factor analysis $(\mathrm{N}=611)$

\begin{tabular}{cccccccc}
\hline Constitutive factor & $\chi^{2}$ & $\mathrm{df}$ & $\chi^{2 / d f}$ & GFI & RMSEA & CFI & NFI \\
\hline HRMS;EPC;OA;EIB & 1863.263 & 1273 & 1.464 & 0.902 & 0.028 & 0.967 & 0.904 \\
HRMS+EIB;OA;EPC & 6254.359 & 1480 & 4.226 & 0.671 & 0.073 & 0.732 & 0.677 \\
HRMS+EIB;OA+EPC & 6083.856 & 1479 & 4.113 & 0.674 & 0.071 & 0.741 & 0.686 \\
HRMS+EPC+OA+EIB & 9380.349 & 1484 & 6.321 & 0.526 & 0.093 & 0.557 & 0.515 \\
\hline
\end{tabular}

Note: "+"representative factor merger. Due to space limitations, both the three-factor model and the two-factor model only list the models with the best fit validity.

\subsection{Descriptive Statistics and Correlation Analysis}

Table 2 Descriptive statistics of variables and Pearson's correlation coefficient

\begin{tabular}{|c|c|c|c|c|c|c|c|c|c|c|c|c|c|}
\hline Variables & Mean & SD & 1 & 2 & 3 & 4 & 5 & 6 & 7 & 8 & 9 & 10 & 11 \\
\hline 1.Gender & 1.602 & 0.490 & 1 & & & & & & & & & & \\
\hline 2.Age & 1.766 & 0.721 & $-.101 *$ & 1 & & & & & & & & & \\
\hline $\begin{array}{l}\text { 3.Education } \\
\text { level }\end{array}$ & 2.046 & 0.922 & 0.077 & -0.053 & 1 & & & & & & & & \\
\hline 4.Unit nature & 2.229 & 1.065 & $.232 * *$ & 0.074 & 0.014 & 1 & & & & & & & \\
\hline 5.Working years & 2.170 & 1.087 & -0.042 & $.446^{* *}$ & $.081 *$ & 0.023 & 1 & & & & & & \\
\hline 6.Job type & 3.241 & 1.630 & 0.052 & 0.030 & $.133 * *$ & $.202 * *$ & $.096^{*}$ & 1 & & & & & \\
\hline 7.Position level & 1.789 & 0.942 & -0.005 & 0.067 & $.264 * *$ & 0.058 & $.251 * *$ & $.115 * *$ & 1 & & & & \\
\hline 8.HRMS & 3.046 & 0.786 & $.112 * *$ & -0.061 & $.127 * *$ & $.083 *$ & 0.007 & $.155^{* *}$ & 0.024 & 1 & & & \\
\hline $9 . \mathrm{OA}$ & 3.346 & 0.692 & $.090 *$ & -0.061 & $.082 *$ & 0.066 & -0.048 & 0.031 & 0.007 & $.627 * *$ & 1 & & \\
\hline 10.EPC & 3.410 & 0.668 & $.103 *$ & 0.011 & 0.051 & -0.009 & 0.004 & 0.000 & 0.042 & $.519 * *$ & $.562 * *$ & 1 & \\
\hline 11.EIB & 3.292 & 0.784 & 0.058 & -0.045 & $.083^{*}$ & 0.044 & -0.007 & 0.008 & 0.041 & $.558 * *$ & $.621^{* *}$ & $.548 * *$ & 1 \\
\hline
\end{tabular}

Note: ${ }^{* * *} p<0.001,{ }^{* *} p<0.01,{ }^{*} p<0.05$, Same below.

The descriptive statistics and correlation coefficients of each variable are shown in Table 2. It can be seen that the correlation between the variables is significant. The study hypothesis has received preliminary support and can be tested in the next step.

\subsection{Hypothesis Test}

This study carried out a hierarchical regression analysis according to the following four steps ${ }^{[18]}$ : (1) the influence of independent variable on dependent variable. The control variables is introduced into the regression equation, and then the independent variable (HRMS) is introduced to analyze the influence of the HRMS on the EIB; (2) the influence of independent variable on mediating variables. Introduce the control variables, and put the independent variable into the regression equation to analyze the influence of the HRMS on the two mediating variables (OA and EPC); (3) the influence of mediating variables on dependent variable. Put the control variables into the regression equation, introduce two mediating variables respectively, and analyze the influence of the two mediating variables on the EIB; (4) mediating effect. Introduce control variables and independent variable, and put two Mediating variables into the regression equation to analyze the HRMS, OA and EPC on EIB. The analysis results are shown in Table 3 .

As shown in Table 3, M6 shows that HRMS significantly positively affects $\mathrm{EIB}(\mathrm{b}=0.564, \mathrm{P}<0.01)$, and $\mathrm{H} 1$ is initially supported. M2 shows that HRMS significantly positively affects $\mathrm{OA}(\mathrm{b}=0.554, \mathrm{P}<0.01)$, and $\mathrm{H} 2$ holds. M7 shows that OA significantly positively affects EIB $(b=0.699, P<0.01)$, and $\mathrm{H} 3$ is initially supported. M4 shows that HRMS significantly positively affects EPC $(b=0.451, P<0.01)$, and H5 holds. M8 shows that EPC significantly positively affects EIB $(b=0.640$, $\mathrm{P}<0.01$ ), and H6 is initially supported. According to M10, HRMS, OA and EPC are all significantly positively affects EIB after the addition of mediating variables $(b=0.220$, $\mathrm{P}<0.01 ; \mathrm{B}=0.394, \mathrm{p}<0.01 ; \mathrm{B}=0.281, \mathrm{P}<0.01)$, and the regression coefficient of HRMS decreased and the change of $\mathrm{F}$ value was significant $(\mathrm{F}=50.694, \mathrm{P}<0.05 ; \mathrm{F}=52.686$, $\mathrm{P}<0.05$ ), indicating that $\mathrm{OA}$ and EPC play mediating role, $\mathrm{H} 4$ and $\mathrm{H} 7$ have received certain support. 
Table 3 Stratified regression analysis results

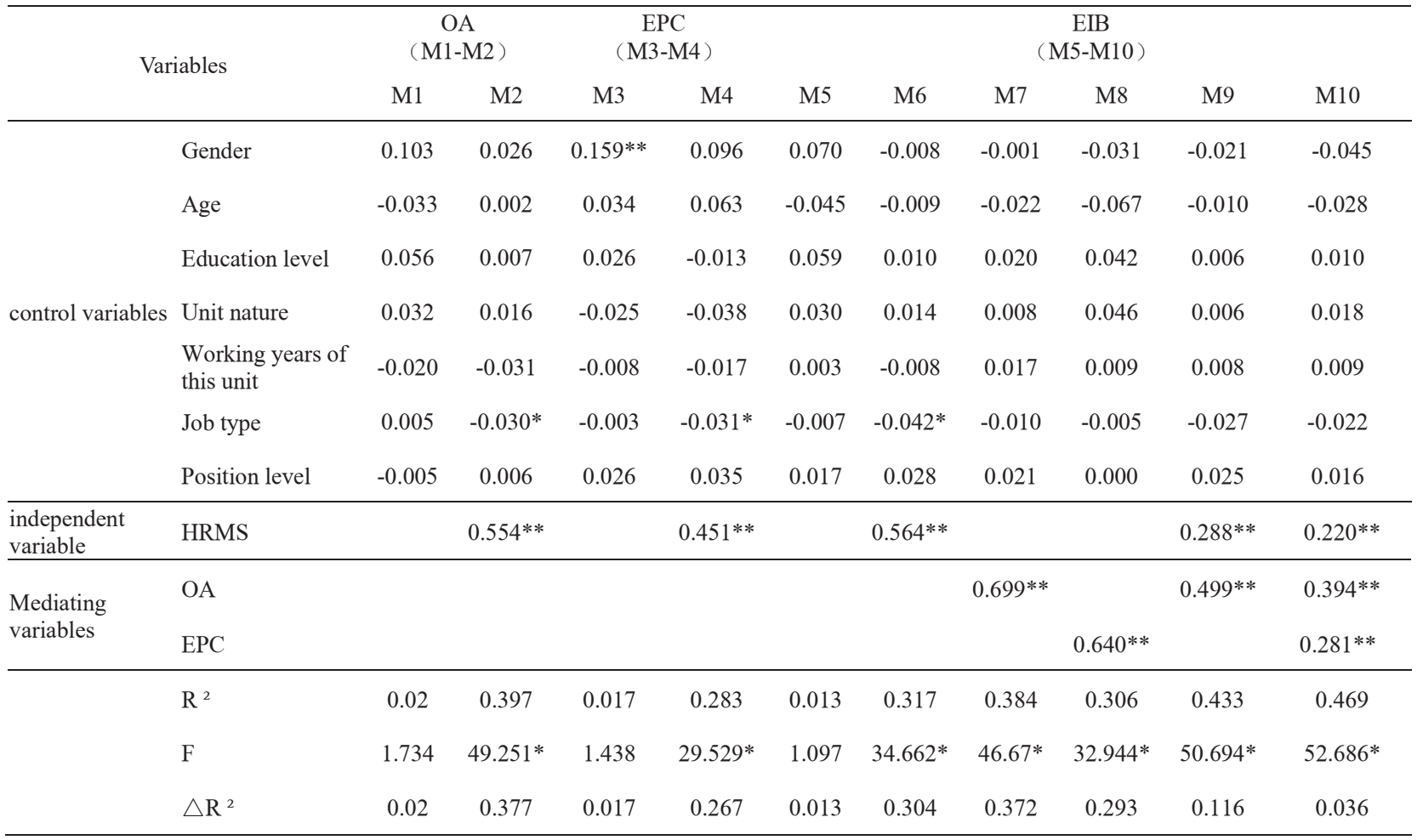

\subsection{Multiple Mediation Effects Test}

In order to further verify the mediation effect, this study tested the multiple mediation effect according to the multiple mediation effect structural equation model test method.

First, a direct effect model is constructed. Mplus 7.4 is used to establish a model that HRMS directly affects EIB, as shown in Figure 2.The fitting indexes of the direct effect model were as follows: $\chi^{2} / \mathrm{DF}=1.758$, RMSEA $=0.035$, CFI $=0.969$, TLI $=0.967$, SRMR $=0.032$. The path coefficient value of IIG $\leftarrow$ HRMS is $0.549(\mathrm{p}<0.001)$, the path coefficient value of IIE $\leftarrow$ HRMS is $0.520(p<0.001)$, the path coefficient value of EIB $\leftarrow$ HRMS is $0.486(\mathrm{p}<0.001)$, It shows that HRMS significantly positively affects EIB and its two stages. H1a and $\mathrm{H} 1 \mathrm{~b}$ are established, $\mathrm{H} 1$ is further verified. All indicators meet the research standards and the next analysis can be carried out.

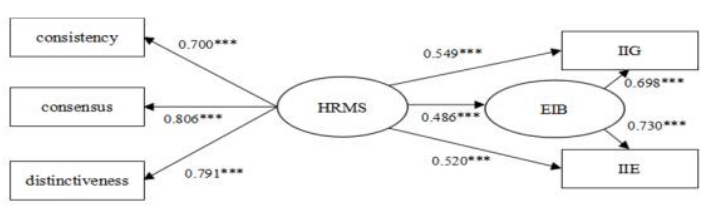

Figure 2 direct effect model

Then compare the complete mediation model (CMM) with the partial mediation model (PMM). In the partial mediation model, HRMS can not only directly affect EIB, but also indirectly affect EIB through OA and EPC. In the complete mediation model, HRMS indirectly influences EIB completely through OA and EPC. The fitting results of the two models are shown in Table 4.

Table 4 Comparison of CMM with PMM

\begin{tabular}{cccccc}
\hline Models & $\chi^{2} / \mathrm{df}$ & RMSEA & CFI & TLI & SRMR \\
\hline CMM & 2.708 & 0.053 & 0.972 & 0.960 & 0.035 \\
PMM & 2.751 & 0.054 & 0.973 & 0.959 & 0.034 \\
\hline
\end{tabular}

Compared with the partially mediated model, the $\chi^{2} /$ DF and RMSEA values of the complete mediated model decreased, and the TLI values increased. In addition, in the partial mediation model, the path coefficient value of $\mathrm{IIG} \leftarrow$ HRMS is $-0.292(\mathrm{p}=0.406$, insignificant $)$, and the path coefficient value of IIE $\leftarrow$ HRMS is $-0.052(p=0.817$, insignificant).Therefore, the complete mediation model with more ideal fitting indexes was accepted in this study (as shown in Figure 3).

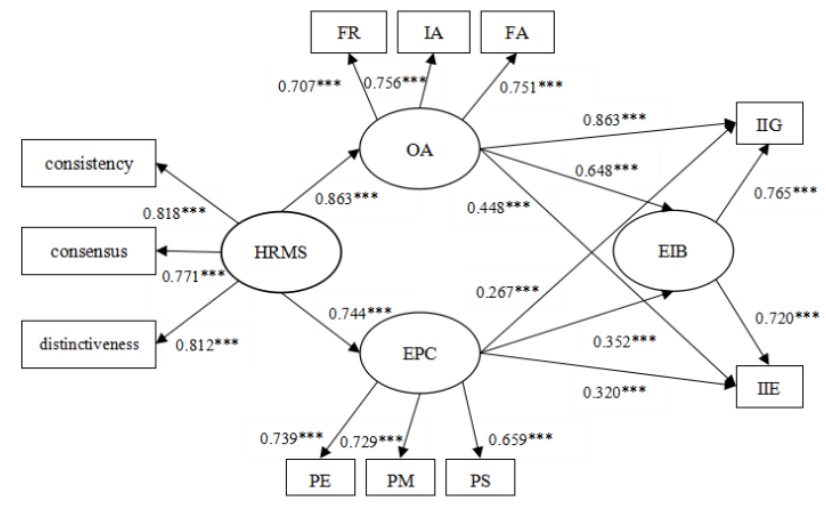

Figure 3 Complete Mediation Model

In complete mediation model, The path coefficient of $\mathrm{IIG} \leftarrow \mathrm{OA}$ is $0.863(\mathrm{p}<0.001)$, the path coefficient of IIE $\leftarrow \mathrm{OA}$ is $0.448(\mathrm{p}<0.001)$, the path coefficient value of $\mathrm{EIB} \leftarrow \mathrm{OA}$ is $0.648(\mathrm{p}<0.001)$, it shows that $\mathrm{OA}$ 
significantly positively effects on EIB and its two stages, $\mathrm{H} 3 \mathrm{a}, \mathrm{H} 3 \mathrm{~b}$ were established, H3 is further verified. The path coefficient of IIG $\leftarrow$ EPC is $0.267(p<0.001)$, the path coefficient value of IIE $\leftarrow \mathrm{EPC}$ is $0.320(\mathrm{p}<0.001)$, the path coefficient value of $\mathrm{EIB} \leftarrow \mathrm{EPC}$ is $0.352(\mathrm{p}<0.001)$. It shows that the EPC significantly affects influence on EIB and its two stages, H6a, H6b were established, H6 is further verified.

Bootstrap test is an ideal method to test the mediating effect $^{[19]}$, so this study chose this method to test multiple mediating effects. The test results were shown in Table 5.
It can be seen from table 5 that the IIG $\leftarrow \mathrm{OA} \leftarrow \mathrm{HRMS}$ path is significant $(b=0.451, p<0.001)$, so H4a holds. The IIE $\leftarrow \mathrm{OA} \leftarrow$ HRMS path is significant $(b=0.314, p<0.001)$, so $\mathrm{H} 4 \mathrm{~b}$ holds. $\mathrm{EIB} \leftarrow \mathrm{OA} \leftarrow \mathrm{HRMS}$ path is significant $(b=0.218, p<0.001)$, so $\mathrm{H} 4$ is further verified. The IIG $\leftarrow$ EPC $\leftarrow$ HRMS path is significant $(b=0.153, p<0.05)$, so $\mathrm{H} 7 \mathrm{a}$ holds. The IIE $\leftarrow \mathrm{EPC} \leftarrow \mathrm{HRMS}$ path is significant $(\mathrm{b}=0.228, \mathrm{p}<0.001)$, so H7b holds. $\mathrm{EIB} \leftarrow \mathrm{EPC} \leftarrow \mathrm{HRMS}$ path is significant $(b=0.127, p<0.001)$, so $\mathrm{H} 7$ is further verified.

Table 5 Bootstrap Test for Mediating Effect

\begin{tabular}{|c|c|c|c|c|}
\hline Paths & Effect & $\mathrm{P}$ & \multicolumn{2}{|c|}{ range } \\
\hline $\mathrm{IIG} \leftarrow \mathrm{EPC} \leftarrow \mathrm{HRMS}$ & 0.153 & 0.017 & 0.025 & 0.282 \\
\hline $\mathrm{IIG} \leftarrow \mathrm{OA} \leftarrow \mathrm{HRMS}$ & 0.451 & 0.000 & 0.319 & 0.602 \\
\hline IIG $\leftarrow$ HRMS (The total effect) & 0.604 & 0.000 & 0.546 & 0.663 \\
\hline IIG $\leftarrow$ HRMS (Contrast mediating effect) & -0.399 & 0.027 & -0.792 & -0.060 \\
\hline $\mathrm{IIE} \leftarrow \mathrm{EPC} \leftarrow \mathrm{HRMS}$ & 0.228 & 0.001 & 0.090 & 0.375 \\
\hline $\mathrm{IIE} \leftarrow \mathrm{OA} \leftarrow \mathrm{HRMS}$ & 0.314 & 0.000 & 0.154 & 0.477 \\
\hline IIE $\leftarrow$ HRMS (The total effect) & 0.542 & 0.000 & 0.472 & 0.609 \\
\hline IIE $\leftarrow$ HRMS (Contrast mediating effect) & -0.123 & 0.572 & -0.556 & 0.307 \\
\hline $\mathrm{EIB} \leftarrow \mathrm{EPC} \leftarrow \mathrm{HRMS}$ & 0.127 & 0.000 & 0.078 & 0.175 \\
\hline $\mathrm{EIB} \leftarrow \mathrm{OA} \leftarrow \mathrm{HRMS}$ & 0.218 & 0.000 & 0.161 & 0.286 \\
\hline $\mathrm{EIB} \leftarrow \mathrm{EPC} \leftarrow \mathrm{HRMS}$ (Contrast mediating effect) & -0.119 & 0.360 & -0.380 & 0.134 \\
\hline $\mathrm{EIB} \leftarrow \mathrm{OA} \leftarrow \mathrm{HRMS}$ (Contrast mediating effect) & -0.157 & 0.287 & -0.135 & 0.438 \\
\hline
\end{tabular}

Further, IIG $\leftarrow$ HRMS total effect path is significant $(b=0.604, p<0.001), I I G \leftarrow H R M S$ contrast intermediary effect path is significant $(b=0.399, p<0.05)$. The results indicate that EPC and OA play the complete mediating role between the HRMS and IIG, and the mediating effect of $\mathrm{OA}$ is stronger than that of EPC.IIE $\leftarrow$ HRMS total effect path is significant $(b=0.542, p<0.001)$, and IIE $\leftarrow$ HRMS contrast intermediary effect path is not significant $(b=0.123, p=0.572)$. It shows that the EPC and OA play the complete mediating role between the HRMS and IIE, and the mediating effect between the OA and the EPC is not significantly different. The comparison of the mediating effect pathways of $\mathrm{IIG} \leftarrow \mathrm{OA} \leftarrow \mathrm{HRMS}$ and IIE $\leftarrow \mathrm{OA} \leftarrow$ HRMS is not significant $(b=-0.157, p=0.287)$. It shows that the mediating effect of HRMS on the IIG and IIE through OA is not significant, and the two effects are similar. The mediating effect pathways of $\mathrm{IIG} \leftarrow \mathrm{EPC} \leftarrow \mathrm{HRMS}$ and $\mathrm{IIE} \leftarrow \mathrm{EPC} \leftarrow \mathrm{HRMS}$ is not significant $(b=-0.119, p=0.360)$. It indicates that the mediating effect of EPC on the impact of HRMS on the IIE and IIG has no significant difference, and the two effects are similar.

\section{CONCLUSION}

\subsection{Research Results}

HRMS is significantly positively affects EIB. OA plays a complete mediating role between HRMS and EIB. EPC plays a complete mediating role between HRMS and EIB. Compared with EPC, OA has a more significant mediating effect on IIG. There is no significant difference between the mediating effect of OA and EPC on IIE. It shows that employees need a good psychological state to generate innovative ideas, and in the process of realizing innovation, OA plays a very important role.

\subsection{Significance}

(1) based on the psychological research paradigm of "S$\mathrm{O}-\mathrm{R}$ ", this study analyzes the mechanism of HRMS on EIB, and adds two psychological variables, OA and EPC, to pay attention to the changes of employees' cognitive ability, psychological state and work behavior caused by HRM measures, which is conducive to the interdisciplinary integration of management and psychology; (2) enterprises need to influence employee cognition through clear institutional support and reward measures, let employees aware of the needs of the organization for innovation activities (OA), and willing to express their innovative ideas (EPC), and make the innovation behaviors expected by the organization.

\subsection{Research Limitations and Prospects}

The shortcomings of this study are as follows: (1) EIB is a two-stage continuous process. Cross-sectional data are adopted in this study, which is not conducive to analyzing the causality between variables. Future research should focus on longitudinal multi-stage investigation; (2) all the questionnaires in this study were filled out by employees, which may have a social approval effect. In future research, comprehensive evaluations of supervisors or colleagues 
can be considered to form mutual confirmation with employees' self-reports to improve the authenticity of the data.

Foundation: Innovation Capability Support Program of Shaanxi Province, China "Research on Leading Innovation Development in Shaanxi Province by Benignordered Flow of Scientific and Technological Talents" (Project No. 2020KRM064).

\section{References:}

1. Amabile T M. A Model of Creativity and Innovation in Organizations [J]. Research in Organizational Behavior, 1988, 10(10):123-167.

2. Saridakis G, Lai Y, Cooper C L. Exploring the relationship between HRM and firm performance: A meta-analysis of longitudinal studies [J]. Human Resource Management Review, 2017, 27(1):87-96.

3. Purcell J, Hutchinson S. Front-line managers as agents in the HRM-performance causal chain: theory, analysis and evidence [J]. Human Resource Management Journal, 2010, 17(1):3-20.

4. Bowen D E, Ostroff B C. Understanding HRM-Firm Performance Linkages: The Role of the "Strength" of the HRM System [J]. Academy of Management Review, 2004, 29(2):203-221.

5. Jia J F, Zhao X D, Zhao R N. How Human Resource Management Strength Affects Employees' Proactive Behavior: Based on Self-Determination Theory [J].Human Resources Development of China, 2020, 37(03):6-17.

6. Lu X J, Zhang G L. The Relationship between Work Motivation and Individual Innovation Behavior [J].Soft Science, 2007(06):124-127.

7. Duan J Y, Wang J J, Zhu Y L. Organizational Climate: A Review of Conceptualization, Theory and Prospects [J].Advances in Psychological Science, 2014, 22(12):1964-1974.

8. Zhu F, Zhang J X, Zhu X J. An Empirical Study on the Influential Mechanism between H R M Strength and Service-oriented OCB: The Mediating Effect of Organizational Commitment and the Moderating Effect of Symbolic Employer Brand[J].Journal of Central University of Finance \& Economics,2020(12):106-114.

9. Amabile T M, Pratt M G. The dynamic componential model of creativity and innovation in organizations: Making progress, making meaning $[\mathrm{J}]$. Research in Organizational Behavior, 2016, 36:157-183.

10. Kahn W A. Psychological Conditions of Personal Engagement and Disengagement at Work [J]. The Academy of Management Journal, 1990, 33(4):692724.

11. Guzzo R A, Noonan K A. Human resource practices as communications and the psychological contract [J]. Human Resource Management, 2010, 33(3):447-462.
12. Liu $\mathrm{X} \mathrm{M}$, Zhang $\mathrm{Y} \mathrm{T}, \mathrm{Xu} \mathrm{C}$. Research on the Configurations of Promoting Employee Innovation Behavior-Qualitative Comparative Analysis Based on Fuzzy Set[J].SCIENCE OF SCIENCE AND MANAGEMENT OF S. \&.T.,2020,41(12):114-128.

13. Liu L, Mei Q, Wu J N. Employee Well-being, Job Stress and Innovation Behavior: Moderating Role of Perceived Organizational Support [J].Science \& Technology Progress and Policy, 2020, 37(07):145151.

14. Yang R J, Shi C L. Conception of integrated model of human resource management intensity affecting employee innovation behavior [J].Finance and Accounting Monthly,2019(19):151-155.

15. Delmotte J, De Winne S, Sels L. Toward an assessment of perceived HRM system strength: scale development and validation [J]. International Journal of Human Resource Management, 2012, 23(7):14811506.

16. Bock G W, Zmud R W, Kim Y G, et al. Behavioral intention formation in knowledge sharing: Examining the roles of extrinsic motivators, social-psychological forces, and organizational climate [J]. Mis- Quarterly, 2005, 29(1):87-111.

17. May D R, Gilson R L, Harter L M. The psychological conditions of meaningfulness, safety and availability and the engagement of the human spirit at work [J]. Journal of Occupational and Organizational Psychology, 2004, 77(1):11-37.

18. Baron R M, Kenny D A. The Moderator-Mediator Variable Distinction in Social Psychological Research: Conceptual, Strategic, and Statistical Considerations [J]. Journal of Personality and Social Psychology, 1987, 51(6):1173-1182.

19. Chen Q M, Wells W D. Attitude toward the Site [J]. Journal of Advertising Research, 1999, 39(5):27-37. 